\title{
Spectral UV measurements in Austria from 1994 to 2006: investigations of short- and long-term changes
}

\author{
S. Simic, P. Weihs, A. Vacek, H. Kromp-Kolb, and M. Fitzka \\ Institute of Meteorology, University of Natural Resources and Applied Life Sciences (BOKU), Vienna, Austria
}

Received: 3 January 2008 - Published in Atmos. Chem. Phys. Discuss.: 8 February 2008

Revised: 2 September 2008 - Accepted: 14 October 2008 - Published: 5 December 2008

\begin{abstract}
The influence of variability of atmospheric parameters on short- and long-term changes of spectral UV irradiance measured at the Sonnblick observatory $\left(47.03^{\circ} \mathrm{N}, 12.57^{\circ} \mathrm{E}, 3106 \mathrm{~m}\right)$ during the period from 1994 to 2006 is studied. Measurements were performed with the Brewer \#093 single-monochromator spectrophotometer and with a Bentham DM 150 spectroradiometer (doublemonochromator).

The influence of ozone, albedo, snowline and clouds on UV variability is evaluated for each parameter separately using 10-year climatology. It is found that the effect of total ozone on short-term variability of UV irradiance at $305 \mathrm{~nm}$ can be more than $200 \%$ and on average more than $50 \%$. Clouds can cause variability of $150 \%$ or more and on average $35 \%$. Variability caused by albedo reaches a maximum of $32 \%$ in April (6\% on average). In summer and autumn, total ozone and clouds strongly influence the variability of UV radiation, whereas in winter and spring ozone has the more pronounced effect. A decrease in snowline height from $3000 \mathrm{~m}$ to $800 \mathrm{~m}$ a.s.l. enhances the UV irradiance by a factor of 1.24 for clear sky conditions and by a factor of 1.7 for $8 / 8$ cloud cover.

Long-term trends are investigated for the time period from 1994 to 2006 based on clear-sky measurements, using the non-parametric Mann-Kendall trend test. Significant downward trends (99\% confidence level) are found for solar zenith angle $55^{\circ}$ at wavelengths from $305 \mathrm{~nm}$ to $324 \mathrm{~nm}$ and erythemally weighted irradiance according to CIE, which are caused by an increase in sunshine duration during periods of high total column ozone. Significant trends (90\% confidence level) were also found for other combinations of wavelength and SZA.
\end{abstract}

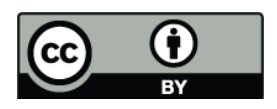

Correspondence to: S. Simic

(stana.simic@boku.ac.at)

\section{Introduction}

UV irradiance reaching the earth's surface is influenced by the concentration of stratospheric ozone as well as by further atmospheric parameters, such as clouds, aerosols, and surface albedo. Knowledge of spectral UV irradiance and its dependence on these parameters, which may change in the future, are prerequisites to quantitatively understand and estimate future UV radiation.

Increase of UV radiation during the last decades is reported where a decrease of stratospheric ozone has been observed (Kerr and McElroy, 1993; Zerefos et al., 1997, 2001; Bartlett and Web, 2000). The magnitude of this change and their causes are, however, uncertain, calling for more detailed investigations of the influence of clouds, albedo, and other atmospheric parameters on UV radiation (Kerr and Seckmeyer et al., 2003; Bais and Lubin et al., 2007).

Several publications focus on the detection of long-term changes in UV doses (Herman et al., 1996; Seckmeyer et al., 1997; Weatherhead et al., 1997; Lindfors et al., 2003). The first spectrally resolved routine measurements started in the 1990s, thus studies on long-term changes in spectral UV irradiance are hampered by the limited number of years of available data (Zerefos et al., 1997; Lakkala et al., 2003; Glandorf et al., 2005).

Clouds can cause strong variability of surface UV radiation (the factor by which incoming surface UV irradiance is enhanced or diminished due to changes in one of the influencing parameters) and limit the detectability of ozoneinduced trends in UV radiation (den Outer et al., 2005; Glandorf et al., 2005; Seckmeyer et al., 2008). Change in cloud cover caused by the global climate change is especially important for the estimation of future UV radiation. Reuder et al. (2001) show that reduced cloud cover during summer can increase UV radiation up to $15 \%$.

Published by Copernicus Publications on behalf of the European Geosciences Union. 
Albedo is of great importance, especially in snow-covered mountainous regions. UV irradiance is strongly enhanced with snow covered ground due to multiple reflections between ground and atmosphere, even more under overcastsky conditions because of increased atmospheric backscattering through clouds. McKenzie et al. (1998) showed that, due to snow, UV-B increased by about $30 \%$ under clear sky and about $70 \%$ under cloudy sky conditions at Lauder, New Zealand. Kylling and Mayer (2001a) investigated the influence of snowline on UV irradiance at $340 \mathrm{~nm}$, studying snow-free conditions and then moving the snowline from 1000 to $0 \mathrm{~m}$. With decreasing snowline, enhancement in UV of 23-27\% for cloudless sky was obtained, while for overcast conditions the enhancement was around 40-60\%.

Different methods are available in literature that separate the different influencing factors causing short- and long-term changes in UV radiation (Fioletov et al., 2001; Kylling et al., 2001b; Arola et al., 2003). Earlier investigations show the effect of ozone on UV radiation, whereas analyzing the influence of clouds and albedo is more difficult. Clouds show strong variability, and measurements of albedo which may be used as model input data are hardly available.

In this study, the influence of clouds, ozone, and surface albedo on spectral UV radiation at the Sonnblick observatory $(3106 \mathrm{~m})$ is investigated using continuous spectral UV irradiance measurements and model calculations. The influence of the different factors on short-term UV variability is shown using the available UV data sets. The method to separate the effects of clouds, ozone, and surface albedo is adapted from Arola et al. (2003) who used this method to analyse measurements at two stations, at Sodankylä, Finland $\left(67^{\circ} \mathrm{N}\right)$ and at Thessaloniki, Greece $\left(40^{\circ} \mathrm{N}\right)$. Spectral UV irradiance time series are analyzed for possible trends. Measurements at Sonnblick observatory starting in 1994 represent the longest time series of spectral UV irradiance data in Austria.

\section{Method}

Monitoring of spectral UV radiation and total ozone at Sonnblick observatory in Austria is performed since 1993. The Sonnblick observatory $\left(47.05^{\circ} \mathrm{N}, 12.95^{\circ} \mathrm{E}\right)$ is in southwest Austria at the border between Salzburg and Carinthia on a mountain top at $3106 \mathrm{~m}$ altitude. It is surrounded by rock faces on the northern side and by a glacier on the southeastern side. The area shows a very pronounced topography. The valley adjacent to Sonnblick is $1300 \mathrm{~m}$ lower than the summit. Nearby summits in this region are at approximately the same altitude. $16 \%$ of the surrounding area is covered with glaciers and in winter $88 \%$ of the surface is covered with snow under the assumption that no snow covers the rock faces (Weihs et al., 1999).

The Sonnblick observatory is a station of the Austrian Weather Office that monitors synoptic and climatological meteorological data. They also record the cloud and ground surface conditions. The cloud fraction above and below the observatory as well as the cloud types are visually observed six times a day. Snowfall and the depth of the snow cover are measured once a day. Snowline is monitored by the weather observers. All this data were used in this study.

\subsection{Instrumentation and measurements}

Spectral UV measurements at Sonnblick observatory have been performed with a Brewer spectrophotometer (single monochromator) since 1993 and a Bentham DM 150 spectroradiometer (double monochromator) since 1997. The Brewer spectrophotometer is used to measure global UV irradiance in the spectral range from $290-325 \mathrm{~nm}$ using a step width of $0.5 \mathrm{~nm}$ and to measure total column ozone. Two independent calibrations are performed on a regular basis (12 months) with a portable $50 \mathrm{~W}$ lamp obtained from SCITEC company and with a self-built portable $1000 \mathrm{~W}$ lampassembly which is calibrated to another NIST (National Institute of Standards and Technology) calibrated $1000 \mathrm{~W}$ lamp in our laboratory. The Bentham spectroradiometer is used to measure global UV irradiance in the spectral range 280$500 \mathrm{~nm}$ with a step width of $0.5 \mathrm{~nm}$. It is calibrated regularly to the self-built $1000 \mathrm{~W}$ lamp-assembly, a NIST calibrated $1000 \mathrm{~W}$ lamp and a PTB (Physikalisch-Technische Bundesanstalt, Germany) calibrated $1000 \mathrm{~W}$ lamp. Comparisons of the Brewer \#093 with the travelling standard (Brewer \#017) and with a Bentham DM 150 spectrometer are performed regularly. Comparisons of total ozone measurements with the standard Brewer-Spectrophotometer \#017 are available since 1993 and show a deviation of less than $1 \%$, and measurements in the UV-B range are within $\pm 5 \%$. Measurements in the UV-B range vary by $\pm 7 \%$ at $305 \mathrm{~nm}$ and by $\pm 4 \%$ at $320 \mathrm{~nm}$ compared to the Bentham spectroradiometer.

The investigations of short and long-term changes were performed with data of the Brewer only. Additional analysis like the influence of snowline on UV-irradiance, is based on Bentham data.

\subsection{Short-term changes in UV-B irradiances}

The analysis is based on UV irradiance measurements performed with the Brewer spectrophotometer. Radiative transfer model calculations were used for the estimation of effects of the contributing factors on the observed variability of UV irradiance. Simulations were carried out with the radiative transfer model SDISORT developed by Stamnes et al. (1988) to determine the influences of ozone, surface albedo, aerosols and clouds on UV variability. In a first step, model calculations based on the actual input data solar zenith angle, total column ozone, surface albedo, clouds and aerosols were performed to reconstruct the actually measured data of the Brewer. 

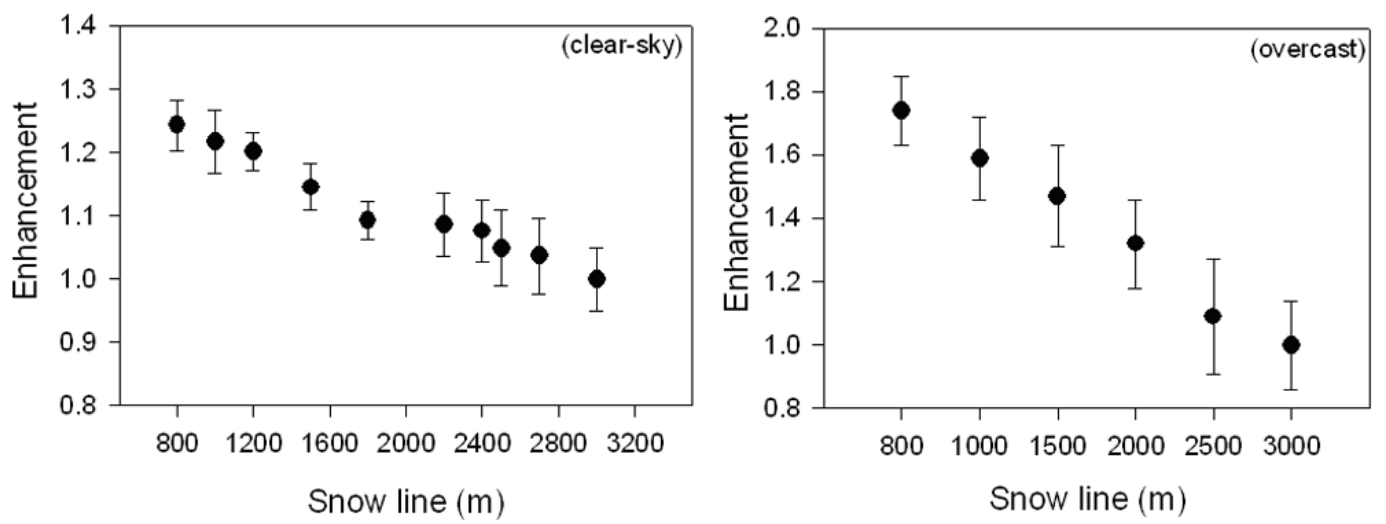

Fig. 1. Measured enhancements in UV irradiance at $305 \mathrm{~nm}$ due to changes in snowline under clear sky (left) and overcast conditions (right). Enhancement due to snowline at a specific altitude is the ratio of UV irradiance with snowline at that given altitude compared to UV irradiance with snowline at $3000 \mathrm{~m}$ a.s.l.

These comparative calculations were performed for measurements at a solar zenith angle of $63^{\circ}$ for the entire period from 1994 to 2003. Then model calculations using climatological and actual input data of the same period were performed at the same SZA.

The daily climatology of each input variable for each day is estimated on the basis of the 10-year data. To calculate the 10-year climatological value of Parameter $X$ on Julian day $Y(\mathrm{JD} Y)$, the values of $X$ are summed up through the years 1994-2003 and then are divided by the number of years (Arola et al., 2003). The formula is given below:

$\bar{X}(\mathrm{JD} Y)=\frac{\sum_{i=1994}^{2003} X(\mathrm{JD} Y)_{i}}{10}$

The influence of a specific parameter $X$ on UV radiation (i.e. the variability of UV irradiance due to parameter $X$ ) is then estimated as the ratio of the modelled radiation using the actual value of parameter $X$ and climatological data of the remaining variables to the modelled radiation using climatic data of all variables, including parameter $X$. The amplitude of each parameter is calculated using Eq. (2):

$A=\frac{\text { max. ratio out of all years }- \text { min. ratio out of all years }}{\text { mean ratio over all years }}$

With this definition, the amplitude $A$ can be regarded as the maximum possible variability in surface UV irradiance caused by parameter $X$. This determining quantity is computed for each influencing parameter. The averaging period was set to one day for short-term and to one month for longterm variability. Additionally, the standard deviation is calculated and regarded the representative quantity for the mean variability during the averaging period.

\subsubsection{Model input data}

Ozone

Daily means of total column ozone from Brewer measurements are the input data to reconstruct the measured UV data. The daily climatology of ozone is calculated as the average of the ozone measurements from 1994 to 2003 according to Eq. (1). Diurnal variations of total column ozone can be as high as $30 \%$ of the daily mean during late winter and spring and up to $10 \%$ during summer and fall (Simic, 2006). Since these fluctuations do not represent climatological changes and make comparison to modelled spectra based on daily data almost impossible, it was decided to further reduce the high variability in the daily climatological mean values of total column ozone by applying a moving-average filter with 11 day period (Julian day $Y \pm 5$ ). This was done for total column ozone only and not for any other input data.

\section{Albedo}

An algorithm is introduced that uses following routine observations of snow condition: Snow height, time since last snowfall and snow line (the latter being defined as the lower altitudinal boundary of the snow-covered area, its altitude is given in meters above sea level). These data were obtained from the Austrian Weather Service and were used to estimate the effective surface albedo in the UV range on a daily basis.

Figure 1 shows the average enhancements of irradiance at $305 \mathrm{~nm}$ with decreasing snowline for clear-sky and overcast conditions. The ordinate shows the ratio of the irradiance at different snowlines and the mean irradiance at a snowline of $3000 \mathrm{~m}$. For clear sky conditions this ratio is 1.24 $( \pm 0.04)$ at snowline of $800 \mathrm{~m}$ and $1.14( \pm 0.03)$ at snowline $1500 \mathrm{~m}$. Cloudiness enhances the influence of the albedo due to multiple reflections between the surface and the lower bond of the clouds. This effect was also studied by Wuttke 


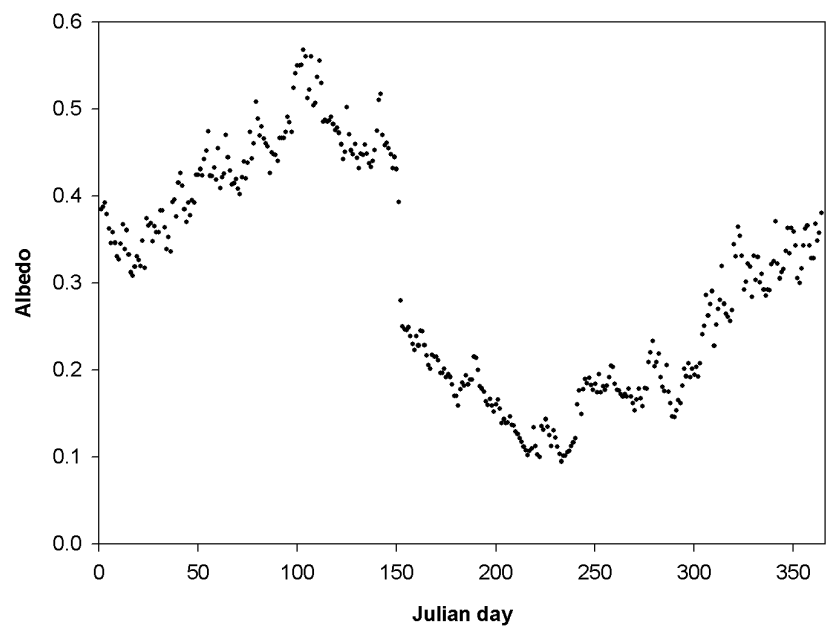

Fig. 2. Calculated daily climatological mean of effective albedo at Sonnblick observatory, computed with Eq. (1), 10-year period.

and Seckmeyer (2006) for conditions in Antarctica. They showed that UV zenith sky radiance may increase by more than a factor of 2, relative to clear sky conditions, due to the combined effect of clouds and high snow albedo. 600 measurements with $8 / 8$ cloud cover were included in Fig. 1 to represent overcast conditions. Under $8 / 8$ cloud cover, UV irradiance at $305 \mathrm{~nm}$ is enhanced by a factor of 1.7 when the snowline is $800 \mathrm{~m}$ instead of $3000 \mathrm{~m}$.

Following the method of Schwander et al. (1999) the "effective albedo" that affects the surface UV irradiance, is derived by parameterisation based upon snow height and time since last snowfall, and by multiple linear regressions between snow condition and albedo, resulting from a best fit of modelled and measured UV irradiances at Sonnblick observatory. This method improves the accuracy of the UV irradiance calculations significantly, compared to a method which uses an albedo averaged over the area of interest. Regression analysis delivered parameterisation of the "effective" albedo $A$ according to Eq. (3):

$A=0.659-2.04 \cdot 10^{-4} \cdot G+4.97 \cdot 10^{-3} \cdot N-3.23 \cdot 10^{-3} \cdot T$

In Eq. (3), $G$ is the snow line (in m a.s.l.), $N$ is the depth of the fresh fallen snow (in $\mathrm{cm}$ ) and $T$ is the time since the last snowfall (in days). Fresh fallen snow increases the effective albedo whereas the albedo decreases with increasing snowline and days after the snowfall. 500 cases were included for calculating regression Eq. (3). The explained variance of this parameterisation is $70 \%$, and the effective albedo varies from 0.02 to 0.89 . Figure 2 shows calculated values of the effective albedo at Sonnblick observatory. Climatological mean values of the albedo determined for the 10 year period are 0.3-0.6 during winter and spring, and 0.09-0.25 during summer. Effective albedo of 0.63-0.78 determined for snowline $800 \mathrm{~m}$ is comparable to the model calculations presented by

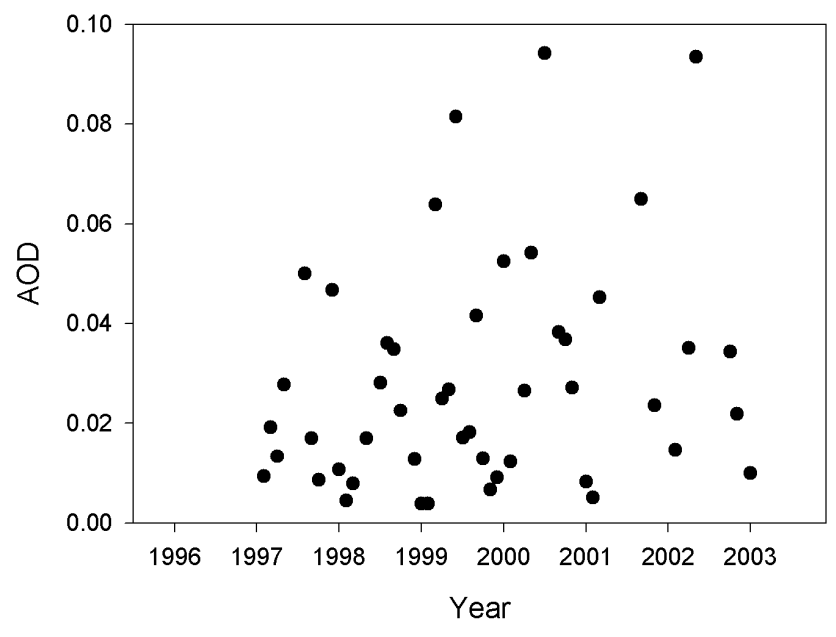

Fig. 3. Monthly means of measurements of aerosol optical depth at $306.3 \mathrm{~nm}$ at Sonnblick observatory.

Weihs et al. (2000). Rengarajan et al. (2000) measured the albedo at the Sonnblick observatory in winter. Their experimentally determined values in the range from 0.73 to 0.78 are well comparable to the albedo values for UVA and visible wavelengths determined in this study at a low snow line of $800 \mathrm{~m}$ a.s.l.

\section{Aerosols}

Observations of direct solar radiation with the Brewer spectrophotometer at five channels $306.3 \mathrm{~nm}, 310.1 \mathrm{~nm}$, $313.5 \mathrm{~nm}, 316.8 \mathrm{~nm}$ and $320.1 \mathrm{~nm}$ were used for the aerosol optical depth (AOD) calculation. Figure 3 shows monthly means of the aerosol optical depth at $306.3 \mathrm{~nm}$ in the period from 1997 to 2002. Optical depths of aerosols at the Sonnblick are 0.03-0.08. Using this range, the calculated variation of UV irradiation is about $3 \%$ at $305 \mathrm{~nm}$ (Weihs et al., 1999). These results underline the fact that aerosols have a small influence on UV irradiance in high mountainous regions.

\section{Clouds}

Model calculations in presence of clouds use the actually observed cloud cover. Cloud transmission data measured with the Bentham DM 150 spectrometer and cloud observations are used in the analysis. Ratios of measured UV intensities and modelled clear sky values (i.e. the cloud modification factor) for the actual zenith angle and ozone amount are used to analyze the dependence of UV irradiance at several wavelengths $(305 \mathrm{~nm}, 315 \mathrm{~nm}, 370 \mathrm{~nm})$ on cloud amount. The study delivers dependencies of the cloud modification factor on total cloud amount, cloud type, wavelength, solar zenith angle and ground albedo, which are used in the present investigation (Simic et al., 2006). 


\subsubsection{Comparison of measured and calculated absolute UV} levels

Calculations of the UV irradiation are performed to test whether they can reproduce the actual irradiance measurements under clear sky condition. In Fig. 4 the ratios of measured and modelled UV irradiances at $305 \mathrm{~nm}$ and solar zenith angle $63^{\circ}$ are shown for the time period 1994-2003. In the period from 1994 to $2003,95 \%$ of the calculated UV irradiances deviate less than $\pm 8 \%$ from the actually measured ones.

\subsection{Long-term changes}

Long-term changes are calculated for different wavelengths $(305 \mathrm{~nm}, 310 \mathrm{~nm}, 315 \mathrm{~nm}, 324 \mathrm{~nm}$ and erythemally weighted irradiances according to CIE) and solar zenith angles $\left(45^{\circ}\right.$, $55^{\circ}$ and $65^{\circ}$ ) from spectra acquired with the Brewer spectrophotometer. Time series from the Brewer have been chosen due to their extent back to 1994 and because of the completeness with no gap longer than three or four weeks appearing throughout the whole period.

The average of the SZAs of the selected measurements does not significantly change during the investigated period. It is therefore unlikely to introduce an artificial trend caused by increasing or decreasing SZAs within the data selection. Monthly mean values are calculated for each combination of wavelength and solar zenith angle for the period from January 1994 to December 2006 except for months with too few data (less than five days per month) or too high cloud cover $(\mathrm{N}>3 / 8)$. As solar zenith angles as high as $45^{\circ}$ are not present from November to February, these months had to be excluded in the analysis of SZA $45^{\circ}$. Measurements at solar zenith angles of $55^{\circ}$ and $65^{\circ}$ are available for all months.

The monthly climatological mean values where obtained by averaging every month over the 13 -year period of investigation. The relative departures from the long-term mean values where computed by comparing monthly mean values to the climatological mean values of the respective month. The time series were checked for the existence of trends using the non-parametric Mann-Kendall (MK) trend-test (Mann, 1945; Kendall, 1975). The results of the MK test were tested against the hypothesis of no detectable trend, i.e. the data being normally distributed. This was done at several significance levels from $\alpha=0.1$ down to $\alpha=0.001$, where $\alpha$ is the probability of rejecting the alternative hypothesis erroneously. The magnitudes of the underlying trends were estimated using two methods of linear regression: the leastsquare method and the non-parametric Theil-Sen slope estimate (Hollander and Wolfe, 1999), the latter being less sensitive to outliers and missing values, which may occur in periods of instrument maintenance and calibration and harsh environmental conditions. The results are shown in percent per decade.

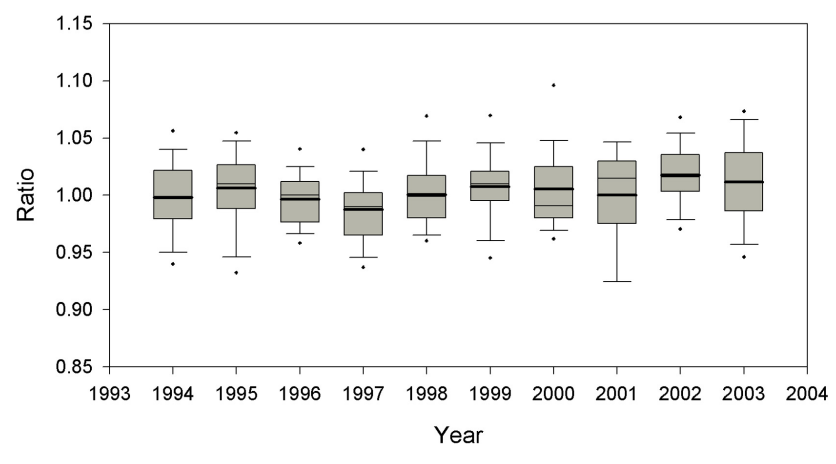

Fig. 4. Ratios of measured to modelled irradiances at $305 \mathrm{~nm}$ and solar zenith angle $63^{\circ}$ in the period from 1994 to 2003 presented in a box plot diagram. The boxes are bounded by the $25 \%$ and $75 \%$ quartile, whiskers denote the $90 \%$ percentile. Calculations are for cloudless conditions only.

To complement the spectra and to enable data filtering for various atmospheric parameters and conditions, detailed 3-hourly cloud and snow observations from the Austrian Weather Service at Sonnblick observatory were included and appended to the appropriate UV-measurements. All spectra were checked and corrected with the SHICrivm algorithm by Slaper (2002). Additionally, the spectra were CIE-weighted and integrated.

It was decided to check for trends in clear-sky spectra $(\mathrm{N} \leq 3 / 8)$ only, thus limiting influencing factors on UVirradiance to any other than cloud cover. Situations with total cloud cover greater than three eighths were omitted. Further reducing the maximum allowed cloud cover $(<3 / 8)$ would have considerably lessened the number of available data-sets. To assure that no artificial trend was introduced by the selection criteria, the partitioning of $0 / 8,1 / 8,2 / 8$ and $3 / 8$ cloud cover was checked for underlying trends over the period 1994 to 2006. No significant change was found using the MK-test. Due to the decreased variations in time series of clear-sky irradiances as opposed to all-sky conditions, significant trends are supposed to be more easily detected in relatively short time series, as proposed by Glandorf et al. (2005).

\section{Results and discussion}

\subsection{Short-term changes}

The influences of total column ozone and albedo on $305 \mathrm{~nm}$ irradiance during the period 1994-2003 is shown in Fig. 5 for April (left column) and August (right column). The ordinate shows the ratio of actual data to daily climatological data. All calculations were performed for a constant solar zenith angle of $63^{\circ}$ for the whole period from 1994 to 2003. Amplitude and standard deviation, as described above, are included. The maximum short-term variability of UV-radiation at $305 \mathrm{~nm}$ due to changes in total column ozone is $186 \%$ in 
Table 1. The amplitude of the influencing factors total ozone, clouds and albedo on UV irradiance at $305 \mathrm{~nm}$ calculated as (maximumminimum)/mean on the basis of daily data. Every single measurement during the time period from 1994 to 2003 is included. Standard deviations are denoted below in italic.

\begin{tabular}{lllllllllllll}
\hline & JAN & FEB & MAR & APR & MAY & JUN & JUL & AUG & SEP & OCT & NOV & DEC \\
\hline \multirow{2}{*}{ ozone } & 2.11 & 2.56 & 1.79 & 1.86 & 1.41 & 1.17 & 1.10 & 1.02 & 1.10 & 1.27 & 1.49 & 1.53 \\
& 0.38 & 0.56 & 0.37 & 0.33 & 0.22 & 0.20 & 0.17 & 0.17 & 0.20 & 0.20 & 0.28 & 0.27 \\
clouds & 1.23 & 1.22 & 1.19 & 1.51 & 1.47 & 1.24 & 1.58 & 1.15 & 1.46 & 1.21 & 1.16 & - \\
& 0.30 & 0.31 & 0.32 & 0.32 & 0.31 & 0.32 & 0.33 & 0.29 & 0.35 & 0.30 & 0.33 & - \\
albedo & 0.27 & 0.26 & 0.31 & 0.32 & 0.21 & 0.15 & 0.12 & 0.14 & 0.13 & 0.18 & 0.24 & 0.23 \\
& 0.04 & 0.05 & 0.04 & 0.06 & 0.04 & 0.03 & 0.03 & 0.02 & 0.02 & 0.04 & 0.04 & 0.04 \\
\hline
\end{tabular}
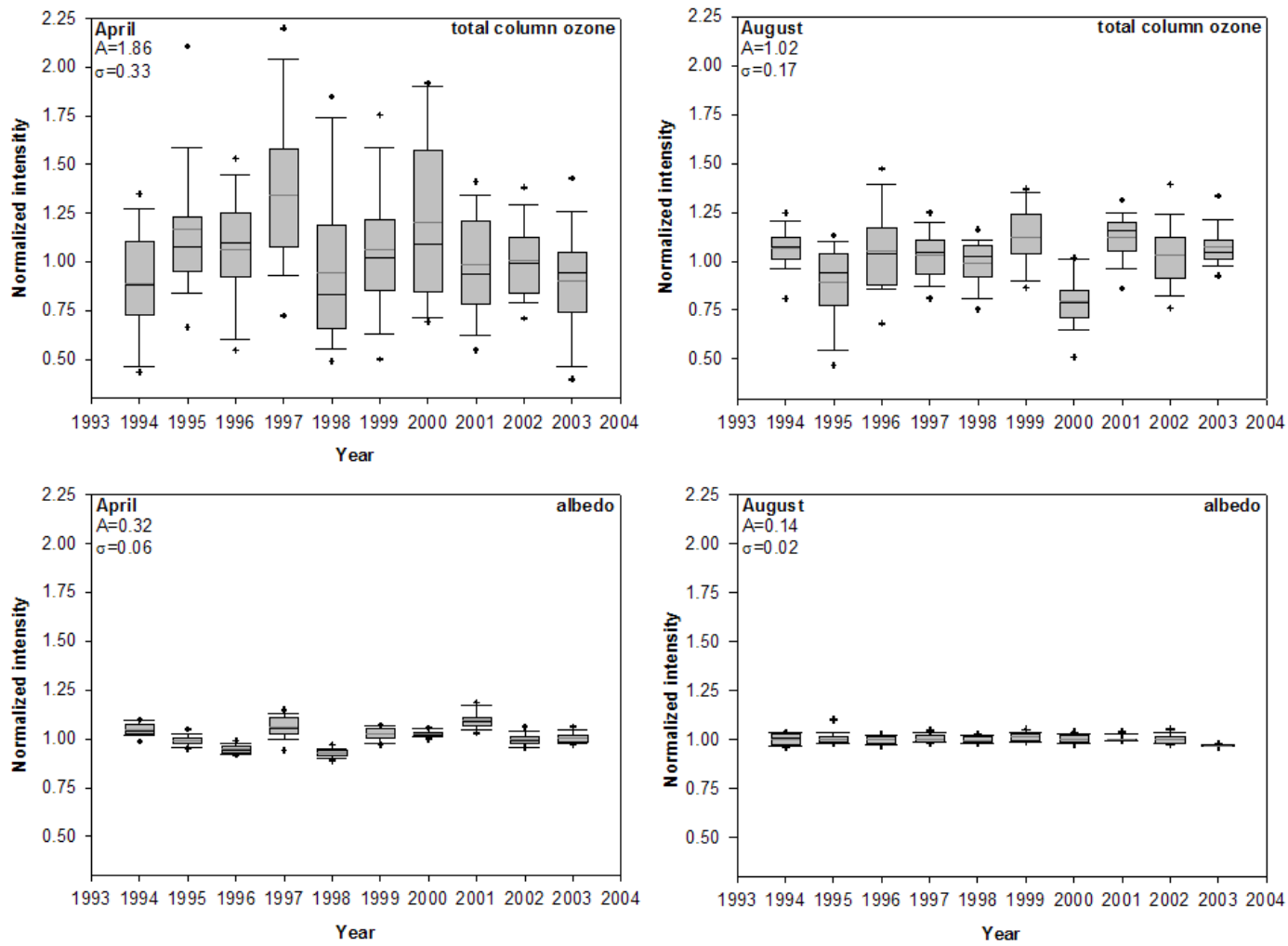

Fig. 5. Box-plot presentation of the influence of total column ozone (top row) and albedo (bottom row) on variability of UV irradiance at $305 \mathrm{~nm}$ in April and August, amplitude $(A)$ and standard deviation $(\sigma)$ are shown in the respective top left corner. The boxes are bounded by the $25 \%$ and $75 \%$ quartile, whiskers denote the $90 \%$ percentile. Normalized intensity is the ratio of the daily mean value of UV irradiance to the 10 -year monthly mean value.

April and $102 \%$ in August. Maximum albedo-induced variability is $32 \%$ in April and 14\% in August. Figure 6 shows the evaluation for May, additionally considering the effects of changing cloud cover. On a short time scale, clouds can alter the surface UV irradiance at $305 \mathrm{~nm}$ by a maximum of $147 \%$.

Model calculations were performed for each month. Table 1 summarizes the results obtained at $305 \mathrm{~nm}$ for the amplitude (representing maximum variability) and for the standard deviation (resembling mean variability over the averaging period): Ozone can affect UV irradiance on a short time scale by up to $200 \%$ (mean variability up to $50 \%$ ). Clouds can cause variability of surface UV irradiance by up to about $150 \%$ (typical mean variability of around $30 \%$ ). Higher levels of attenuation are found in literature: Because of Sonnblick being a high altitude mountain site (3106 ma.s.l.), the layer-thickness of the observed clouds is smaller, therefore the attenuation of UV-irradiance is reduced (Blumthaler et al., 1996). Additionally, the increase of albedo with altitude compensates for the attenuation by 

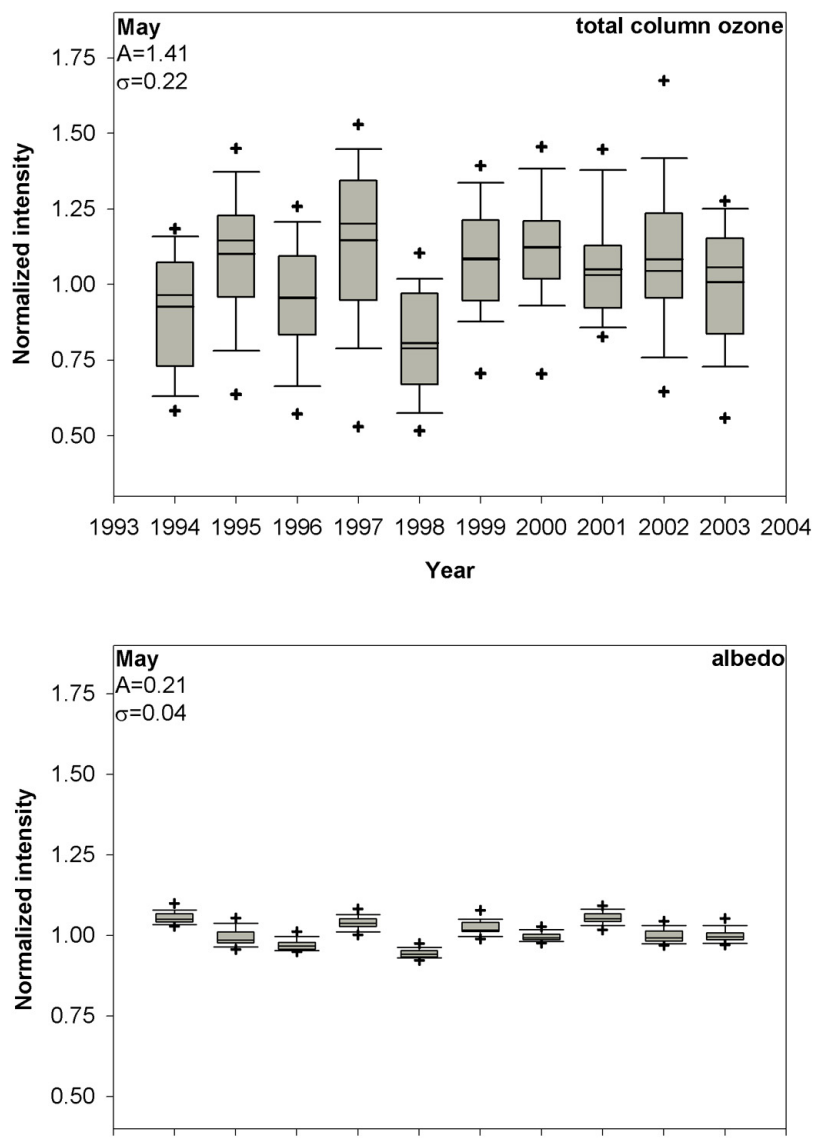

199319941995199619971998199920002001200220032004 Year

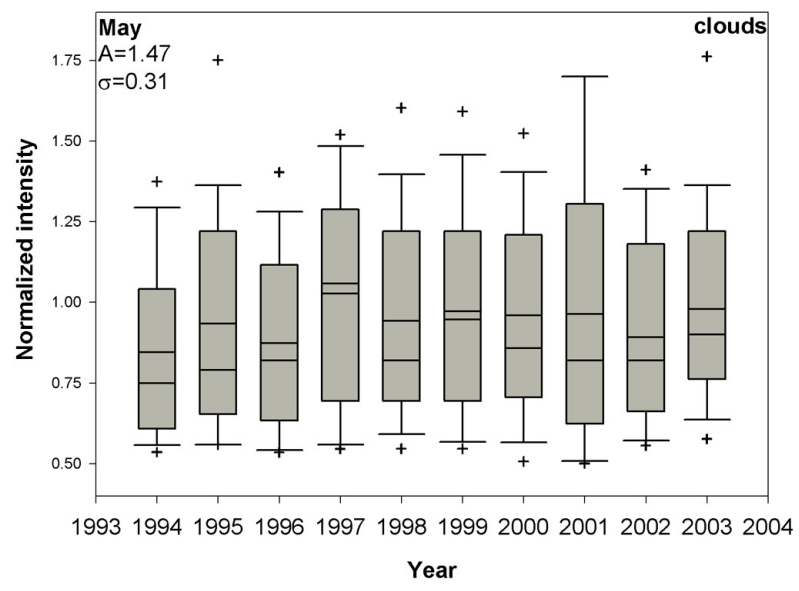

Fig. 6. Box-plot presentation of the influence of total column ozone, clouds and albedo on variability of UV irradiance at $305 \mathrm{~nm}$ for May. The boxes are bounded by the $25 \%$ and $75 \%$ quartile, whiskers denote the $90 \%$ percentile. Ozone and clouds are the dominating influences whereas the contribution of albedo is small.

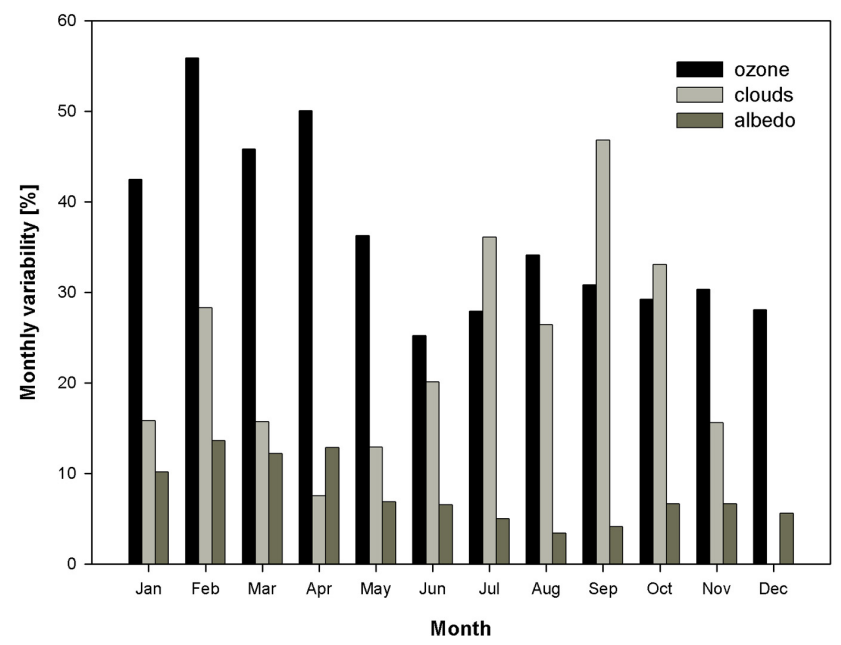

Fig. 7. Maximum variation in monthly mean values of $305 \mathrm{~nm}$ irradiance caused by total column ozone, clouds and albedo.

clouds to some extent. Simic (2006) found, that an increase in Albedo from 0.18 to 0.4 at Hoher Sonnblick may decrease attenuation of UV irradiance on average by $21 \%$ at eight octa cloud cover.

Albedo has the greatest influence on the variation of UV irradiance in April as this is the period of snow-melt, which causes the snowline (and thus the effective albedo) to change significantly on a relatively short time-scale. During summer, clouds contribute the major part of variability whilst ozone dominates in spring. This is explained by the strong variability of total column ozone during winter and spring and the enhanced cumulus convection during summer.

Figure 7 shows the maximum variability in monthly mean values of $305 \mathrm{~nm}$ irradiance induced by total column ozone, clouds and albedo. The effect of ozone on short-time variability of monthly mean irradiance can be more than $50 \%$ in spring whereas the effect of clouds is largest during summer and early autumn. Variability caused by albedo ranges from $3 \%$ to $13 \%$.

Investigations by Arola et al. (2003) for the station Sodankylä $\left(67^{\circ} \mathrm{N}, 191 \mathrm{~m}\right.$ a.s.l.) in Finland show that the effect of total ozone on short-term variability of monthly mean UV irradiance at $305 \mathrm{~nm}$ can be almost $100 \%$, rather than the $50 \%$ found at Sonnblick. The greater effect of ozone found at the arctic station Sodankylä may be explained through the stronger interannual variation of ozone concentration at high latitudes. Variability caused by albedo in May in Sodankylä is $21 \%$ (average at monthly level $7 \%$ ) and $32 \%$ (average at monthly level 6\%) is found at the Sonnblick observatory. Thus variability caused by albedo is in the same range at both stations.

Clouds can alter incoming UV-irradiance by up to $200 \%$ in Sodankylä compared to a maximum of $147 \%$ at Sonnblick during the summer months: as a consequence of reduced 
Table 2. Linear trends in relative departures of UV radiance from climatological monthly mean values, wavelengths from 305 to $324 \mathrm{~nm}$ and CIE, solar zenith angles of $45^{\circ}, 55^{\circ}$ and $65^{\circ}$ are evaluated for the time period 1994-2006. Trends are calculated with the Theil-Sen method and are given in percent per decade, symbols to the right indicate the significance of the trend $\left[^{-}:\right.$insignificant $(\alpha>0.1),{ }^{+}$: significant $(\alpha \leq 0.1), *$ : highly significant $\left.(\alpha \leq 0.01)\right]$.

\begin{tabular}{lrrrrr}
\hline SZA & $305 \mathrm{~nm}$ & $310 \mathrm{~nm}$ & $315 \mathrm{~nm}$ & $324 \mathrm{~nm}$ & $\mathrm{CIE}$ \\
\hline $45^{\circ}$ & $-9.5^{+}$ & $-11.1^{+}$ & $-10.5^{+}$ & $-9.8^{+}$ & $-10.3^{+}$ \\
$55^{\circ}$ & $-23.9^{*}$ & $-19.9^{*}$ & $-15.6^{*}$ & $-14.4^{*}$ & $-19.5^{*}$ \\
$65^{\circ}$ & $-3.8^{-}$ & $-5.7^{+}$ & $-4.6^{+}$ & $-6.0^{+}$ & $-4.4^{-}$ \\
\hline
\end{tabular}

cloud layer thickness at high altitudes, the effect of attenuation is less pronounced at the latter station. At the Mediterranean site of Thessaloniki $\left(40^{\circ}\right)$, Arola et al. found the variability due to aerosols to be in the same range as variability due to clouds, which is quite different at Sonnblick: the very small values of aerosol optical depth and the changes therein do not cause more than $3 \%$ variation.

\subsection{Long-term changes}

Figure 8 shows relative departures of UV radiance from climatological monthly mean values. As stated in chapter 2.3 , only clear-sky spectra were included. Wavelengths of $305 \mathrm{~nm}, 310 \mathrm{~nm}, 324 \mathrm{~nm}$ and erythemally weighted irradiances according to CIE at solar zenith angles of $45^{\circ}, 55^{\circ}$ and $65^{\circ}$ are shown for the time period from 1994 to 2006. Data are approximated with linear regression lines and the results are shown in percent per decade. Trends given in the upper right corner are calculated with the Theil-Sen method. Symbols in parenthesis indicate the significance of the trend $[(-)$ : insignificant $(\alpha>0.1),(+)$ : significant $(\alpha \leq 0.1),(*)$ : highly significant $(\alpha \leq 0.01)$ ]. In Table 2 , the results of the evaluations are summarized. Calculations are also performed with the least-square method, and the obtained results coincide well in cases with highly significant trends. In addition to the MK-test, the series where checked for the minimum time period necessary to reliably detect underlying trends of the found magnitude at a significance level of at least $90 \%$, as proposed by Weatherhead et al. (1998). It was shown, that the number of years required does not exceed the 13 years of available data for all of the time series that exhibit a highly significant trend.

For a wavelength of $305 \mathrm{~nm}$, downward trends of $-9 \% / \mathrm{dec}$ at solar zenith angle $45^{\circ}(90 \%$ confidence level) and $-24 \% / \mathrm{dec}$ at $55^{\circ}(99 \%$ confidence level) are determined for the period from 1994-2006. The trend is highly significant for $55^{\circ} \mathrm{SZA}$, where the largest data set is available. Analysis of $310 \mathrm{~nm}, 315 \mathrm{~nm}$ and $324 \mathrm{~nm}$ basically delivers a comparable behaviour, however the trends are somewhat smaller, i.e. the regression-line slopes becoming less negative as the wavelength increases. Trends found in CIE integrated monthly mean values consequently show smaller decreases than those found at $305 \mathrm{~nm}$ but they are steeper than those at $315 \mathrm{~nm}$ and $324 \mathrm{~nm}$.

Decrease of UV irradiance at short wavelengths would suggest an increase in stratospheric ozone during the investigation period from 1994 to 2006 . Total ozone measurements performed with the Brewer spectrophotometer at the Sonnblick observatory, however, do not show this trend, as the small decrease of $-3.67 \% / \mathrm{dec}$ in monthly means that include all ozone measurements, was found not to be significant using the Mann-Kendall trend-test. Following the method of Weatherhead et al. (1998), the series would have to extend over more than 87 years to exhibit a trend at $90 \%$ significance level. Thus, further analysis of all other influencing factors was required to explain those significant downward trends.

Checking for long term changes in time series of cloud cover and reconstructed albedo (calculated with Eq. 3) to possibly account for the changes in UV-irradiance also did not identify significant linear trends over the period 19942006: The time-series of reconstructed albedo would have to extend over more than 50 years for the downward trend of $-3.9 \%$ per decade to be significant at a level of at least $90 \%$. Likewise, the small downward trend of $-0.02 \%$ dec contained in total cloud cover observations during the investigated period is insignificant. There was no significant change detected in partitioning of octa cloud cover either. On the contrary, sunshine duration has increased by up to $9.6 \% / \mathrm{dec}$ of the 13-year monthly mean values during 1994-2006 at Hoher Sonnblick. The largest increases were found during spring and summer. In spring, the highest total column ozone values of the year are to be found: The 13-year monthly mean values of total column ozone during the first half-year were found to be about $14 \%$ higher than the respective values during July to December. This explains the observed highly significant downward trends, since more UV-irradiance measurements during higher total column ozone concentrations were included in the latter parts of the investigation period. At a solar zenith angle of $55^{\circ}$, a significant increase of almost $19 \% / \mathrm{dec}$ in the number of available clear-sky spectra is present over the whole period. At the same time, the increase in the number of available clear-sky spectra during January to June only is almost $45 \% / \mathrm{dec}$. This may also explain the fact that the 13-year monthly mean irradiances at 305 and $310 \mathrm{~nm}$ and the CIE integrated irradiances are up to $16 \%$ smaller during January to June than during the second half-year. The same pattern can be recognized at $45^{\circ}$ and $65^{\circ}$ SZA. However, at these SZAs fewer data are available and the trends in sunshine duration are less pronounced.

Additionally, time series containing measurements under all-sky conditions were analysed for underlying trends. In general, they show the same behaviour as those containing clear-sky measurements only, revealing downward trends at several combinations of SZA and wavelength: At $55^{\circ} \mathrm{SZA}$, 

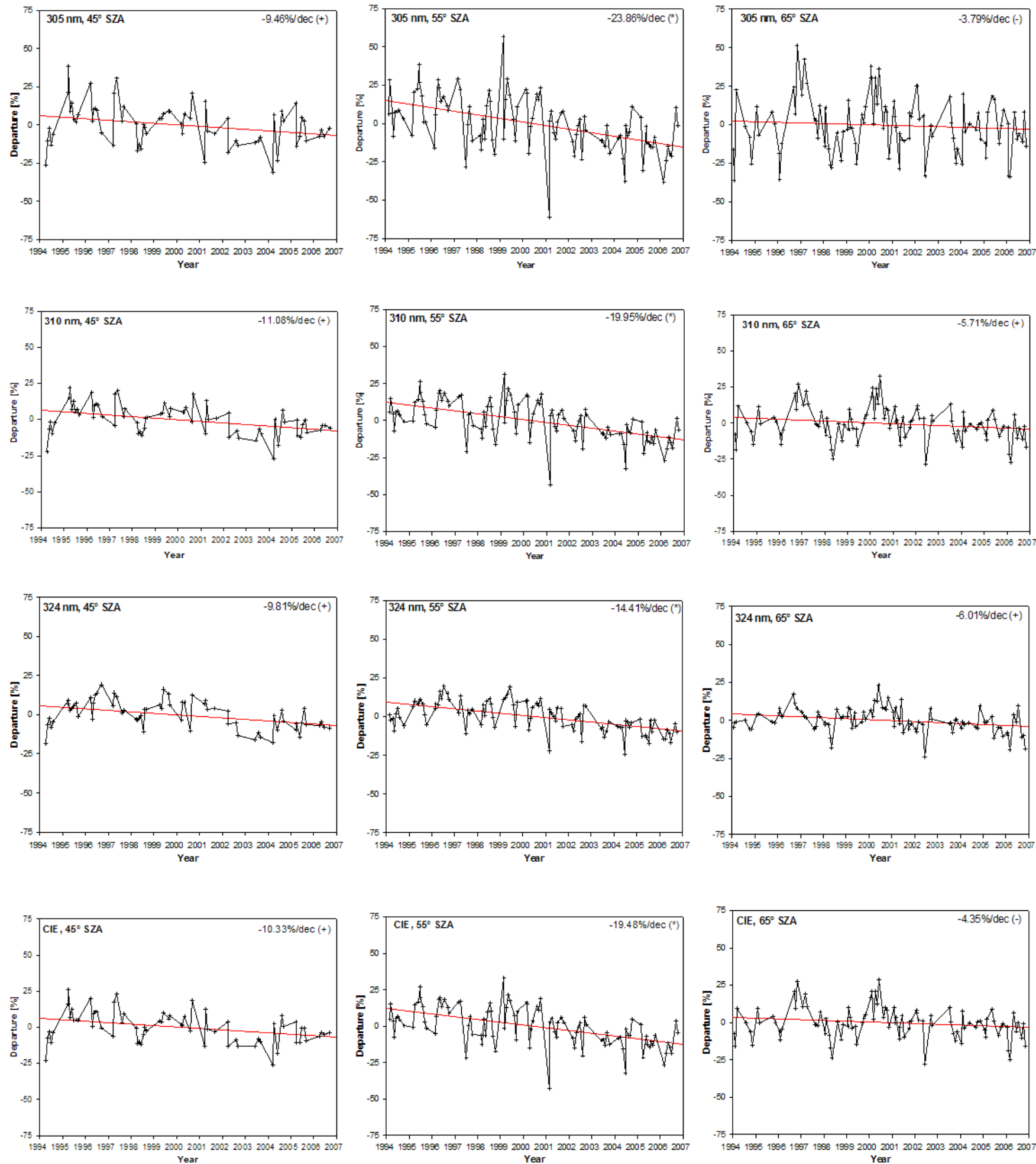

Fig. 8. Relative departures of UV irradiance from climatological monthly mean values, wavelengths of $305 \mathrm{~nm}$ (first row), $310 \mathrm{~nm}$ (second row), $324 \mathrm{~nm}$ (third row) and erythemally weighted irradiance according to CIE (fourth row) are shown for solar zenith angles of $45^{\circ}$ (first column), 55 (second column) and $65^{\circ}$ (third column), data from 1994 to 2006 are approximated with linear regression lines using the TheilSen method, symbols in parenthesis indicate trend significance [(-): insignificant $(\alpha>0.1)$, (+): significant $(\alpha \leq 0.1),(*)$ : highly significant $(\alpha \leq 0.01)]$. 
downward trends of down to $-23 \% / \mathrm{dec}$ were found at $90 \%$ significance level for erythemally weighted irradiance as well as for $310 \mathrm{~nm}$ under all-sky conditions. Downward trends found at $45^{\circ} \mathrm{SZA}$ compared well to clear-sky conditions, the significance level being $90 \%$ for wavelengths of $290 \mathrm{~nm}$ and higher. However, caused by the enhanced variation due to cloud-cover in all-sky data, fewer trends were found as highly significant compared to the analysis of clear-sky spectra only. This is especially true with all-sky data at $65^{\circ} \mathrm{SZA}$, where no significant trend was detected at all. Much longer time series (longer than 20 years on average) would have been needed to detect significant long-term changes under all-sky conditions.

In Sodankylä, Finland, spectral irradiance at $305 \mathrm{~nm}$ in April decreases when the time period from 1993 to 2001 is investigated whereas it increases considering the period from 1990 to 1997 (Lakkala et al., 2003). Investigations of longterm variability of monthly mean solar spectral irradiance at $305 \mathrm{~nm}$ and $324 \mathrm{~nm}$ in Thessaloniki, Greece show positive trends at both wavelengths for the period 1990-2006 (Bais et al., 2007). The investigated time period has a strong influence on the calculated long-term change of spectral UV irradiance at Sonnblick observatory. When spectra measured during the time period from 1994 to 2001 are analysed, mainly positive trends are found for different wavelengths and solar zenith angles (Simic, 2005). Glandorf et al. (2005) evaluated several wavelengths and solar zenith angles of the longest spectral UV irradiance measurements in Europe, in Thessaloniki and Sodankylä. They conclude that even the longest series are too short to show distinct trends due to the large variability of UV irradiance.

\section{Summary}

The influence of ozone, clouds, and surface albedo on spectral UV radiation at the Sonnblick observatory $(3106 \mathrm{~m})$ is investigated using continuous spectral UV irradiance measurements and model calculations. Measurements at Sonnblick observatory starting 1994 represent the longest time series of spectral UV irradiance data in Austria and are used in the present investigation.

1. UV irradiance at wavelength $305 \mathrm{~nm}$ under clear sky condition is modelled and compared with the actual measurements. In $95 \%$ of the investigated cases throughout the period from 1994 to 2003, the calculated UV irradiations are maximum 12\% higher and $8 \%$ lower than actually measured irradiations. The determination of the effective albedo at the observatory is essential for a good correlation of measurement and model. The determination of the effective albedo uses the snow line altitude, the depth of the fresh fallen snow and the time since last snowfall.
2. Measurements at Sonnblick observatory at $305 \mathrm{~nm}$ show a pronounced influence of snowline height on surface UV irradiance. A decrease in snowline height from $3000 \mathrm{~m}$ to $800 \mathrm{~m}$ a.s.l. enhances the UV irradiance by a factor of 1.24 for clear sky conditions and by a factor of 1.7 for $8 / 8$ cloud cover.

3. Short-term variability of UV irradiance at $305 \mathrm{~nm}$ because of changes in ozone can be more than 200\% (more than $50 \%$ on average). Clouds can cause variability of $150 \%$ or more (average $35 \%$ ). Maximum variability caused by albedo is $32 \%$ in April (average 6\%) and 12$15 \%$ in the summer months (average 3\%). In summer and autumn, total ozone and clouds strongly influence the variability of UV radiation, whereas in winter and spring ozone has the more pronounced effect.

4. Spectral UV irradiance at $305 \mathrm{~nm}, 310 \mathrm{~nm}, 324 \mathrm{~nm}$ and CIE at solar zenith angles of $45^{\circ}, 55^{\circ}$ and $65^{\circ}$ from 1994-2006, taken from measurements under clearsky conditions, were analyzed for possible trends. Significant downward trends (99\% confidence level) were found for solar zenith angle $55^{\circ}$ at all wavelengths. At solar zenith angles of $45^{\circ}$ and $65^{\circ}$, downward trends of UV irradiance were found for several wavelengths (90\% confidence level). These trends can be explained through an increase in the number of measurements under the influence of high total column ozone over the investigated period.

Acknowledgements. This work has been funded by the Austrian Ministry for Environment and by the Commission of the European Communities, project "Stratosphere-Climate Links with Emphasis on the UTLS, Scout-03".

Edited by:: J. Groebner

\section{References}

Arola, A., Lakkala, K., Bais, A., Kaurola, J., Meleti, C., and Taalas, P.: Factors affecting short- and long-term changes of spectral UV irradiance at two European stations, J. Geophys. Res., 108(17), 9, 1-11, 2003.

Bais, A., Lubin, D., Arola, A., Bernhard, G., Blumthaler, M., Chubarova, N., Erlick, C., Gies, H., Krotkov, N., Lamtz, K., Mayer, B., McKenzie, R., Piacentini, R., Seckmeyer, G., Slusser, J., Zerefos, C., Feister, U., Fioletov, V., Gröbner, J., Kyrö, E., and Slaper, H.: Surface ultraviolet radiation: past, present and future, Scientific assessment of ozone depletion: 2006, 7(21), 154, 2007.

Bartlett, L. M. and Webb, A. R.: Changes in ultraviolet radiation in the 1990s: Spectral measurements from Reading, England, J. Geophys. Res.-Atmos., 105(D4), 4889-4893, 2000.

Blumthaler, M., Ambach, W., Cede, A., and Staehelin, J.: Attenuation of erythemal effective irradiance by cloudiness at low and high altitude in the Alpine region, Photochem. Photobiol., 63(2), 193-196, 1996. 
den Outer, P. N., Slaper, H., and Tax, R. B.: UV radiation in the Netherlands: Assessing long-term variability and trends in relation to ozone and clouds, J. Geophys. Res., 110, D02203, doi:10.1029/2004JD004824, 2005.

Fioletov, V., McArthur, B., Kerr, J., and Wardle, D.: Longterm variations of UV-B irradiance over Canada estimated from Brewer observations and derived from ozone and pyranometer measurements, J. Geophys. Res., 106, 23 009-23 028, 2001.

Glandorf, M., Arola, A., Bais, A., and Seckmeyer, G.: Possibilities to detect trends in spectral UV irradiance, Theor. Appl. Climatol., 81, 33-44, 2005.

Herman, J. R., Bhartia, P. K., Kiemke, J., Ahmad, Z., and Larko, D.: UV-B increases (1979-1992) from decreases in total ozone, Geophys. Res. Lett., 23, 2117-2120, 1996.

Hollander, M. and Wolfe, D. A.: Nonparametric statistical methods (2nd Edn.), New York, John Wiley \& Sons, 421-423, 1999.

Kendall, M. G.: Rank correlation methods, Griffin London, 202 pp., London, 1975.

Kerr, J. B. and McElroy, C. T.: Evidence for large upward trends of Ultraviolet-B radiation linked to ozone depletion, Science, 262, 1032-1034, 1993.

Kerr, J., Seckmeyer, G., Bais, A., Blumthaler, M., Diaz, S. B., Krotkov, N., Lubin, D., Madronich, S., McKenzie, R. L., Sabzipavar, A.-A., and Verdebout, J.: Surface ultraviolet radiation: Past and future, Chapter 5 in Scientific Assessment of Ozone Depletion: 2002, Global Ozone Research and Monitoring Project Report No. 47, WMO, Geneva, Switzerland, 2003.

Kylling, A. and Mayer, B.: Ultraviolet radiation in partly snow covered terrain: Observations and three-dimensional simulations, Geophys. Res. Lett., 28, 3665-3668, 2001a.

Kylling, A., Dahlback, A., and Mayer, B.: The effect of clouds and surface albedo on UV irradiances at a high latitude site, Geophys. Res. Lett., 27, 1411-1414, 2001 b.

Lakkala, K., Kyrö, E., and Turunen, T.: Spectral UV measurements at Sodankylä during 1990-2001, J. Geophys. Res., 108(D19), 4621, doi:10.1029/2002JD003300, 2003.

Lindfors, A. V., Arola, A., Kaurola, J., Taalas, P., and Svenøe, T.: Long-term erythemal UV doses at Sodankylä estimated using total ozone, sunshine duration, and snow depth, J. Geophys. Res., 108(D16), 4518, doi:10.1029/2002JD003325, 2003.

Mann, H. B.: Nonparametric tests against trend, Econometrica, 13, 245-259, 1945.

McKenzie, R. L., Paulin, K. J., and Madronich, S.: Effects of snow cover on UV irradiance and surface albedo: A case study, J. Geophys. Res., 103(28), 785-792, 1998.

Rengarajan, G., Weihs, P., Simic, S., Mikielewicz, W., Laube, W.: Albedo measurements system for UVA and the visible wavelength, Radiat. Prot. Dosim., 91, No 1-3, 197-199, 2000.

Reuder, J., Dameris, M., and Koepke, P.: Future UV radiation in Central Europe modelled from ozone scenarios, J. Photochem. Photobiol. B. Biol., 61(3), 94-105, 2001.
Schwander, H., Mayer, B., Ruggaber, A., Albold, A., Seckmeyer, G., and Koepke, P.: Method to Determine Snow Albedo Values in the Ultraviolet for Radiative Transfer Modeling, Appl. Optics, 38(18), 3869-3875, 1999.

Seckmeyer, G., Mayer, B., Bernhard, G., Erb, R., Albold, A., Jäger, H., and Stockwell, W. R.: New maximum UV irradiance levels observed in Central Europe, Atmos. Environ., 31, 2971-2976, 1997.

Seckmeyer, G., Pissull, D., Glandorf, M., Henriques, D., Johnsen, B., Webb, A., Siani, A., Bais, A., Kjeldstad, B., Brogniez, C., Lenoble, J., Gardiner, B., Kirsch, P., Koskela, T., Kaurola, J., Uhlmann, B., Slaper, H., den Outer, P., Janouch, M., Werle, P., Gröbner, J., Mayer, B., de la Casiniere, A., Simic, S., and Carvalho, F.: Variability of UV irradiance in Europe, Photochem. Photobiol., 84, 172-179, 2008.

Simic, S.: Investigations on the transfer of ultraviolet radiation on the Hoher Sonnblick, doctoral thesis, BOKU Vienna, 2006.

Slaper, H.: SHICrivm, www.rivm.nl, last access: July 2002.

Stamnes, K., Tsay, S. C., Wiscombe, W., and Jayaweera, K.: Numerically stable algorithmn for discrete-ordinate-method radiative transfer in multible scattering and emitting layered media, Appl. Optics, 27, 2502-2509, 1988.

Weatherhead, E. C., Tiao, G. C., Reinsel, G. C., Frederick, J. E., DeLuisi, J. J., Choi, D. S., and Tam, W. K.: Analysis of long-term behavior of ultraviolet radiation measured by Robinson-Berger meters at 14 sites in the United States., J. Geophys. Res., 102, 8737-8754, 1997.

Weatherhead, E. C., Reinsel, G. C., Tiao, G. C., Meng, X., Choi, D., Cheang, W., Keller, T., DeLuisi, J., Wuebbles, D. J., Kerr, J. B., Miller, A. J., Oltmans, S. J., and Frederick, J. E.: Factors affecting the detection of trends: Statistical considerations and applications to environmental data, J. Geophys. Res., 103 17 179-17 161, 1998.

Weihs, P., Simic, S., Laube, W., Mikielewicz, W., Rengarajan, G., and Mandl, M.: Characteristics of clear sky surface UV irradiance at high mountain observatory Sonnblick (3106 m altitude), J. Appl. Meteorol, 38(11), 1599-1610, 1999.

Weihs, P., Scheifinger, H., Rengarajan, G., and Simic, S.: Effect of topography on average surface albedo in the ultraviolet wavelength range, Appl. Optics, 39, 3592-3603, 2000.

Wuttke, S., Seckmeyer, G., and König-Langlo, G.: Measurements of spectral snow albedo at Neumayer, Antarctica, Ann. Geophys., 24, 7-21, 2006, http://www.ann-geophys.net/24/7/2006/.

Zerefos, C. S., Balls, D. S., Bais, A., Gillotay, D., Simon, P. C. Mayer, B., and Seckmeyer, G.: Variability of UV-B at four stations in Europe, Geophys. Res. Lett., 24(11), 1363-1366, 1997.

Zerefos, C., Balis, D., Tzortziou, M., Bais, A., Tourpali, K., Meleti, C., Bernhard, G., and Herman, J.: A note on the interannual variations of UV-B erythemal doses and solar irradiance from ground-based and satellite observations, Ann. Geophys., 19(1), 115-120, 2001. 